\title{
Expression profiles of eNOS, iNOS and microRNA-27b in the corpus cavernosum of rats submitted to chronic alcoholism and Diabetes mellitus ${ }^{1}$
}

Joao Paulo da Cunha', Fermino Sanches Lizarte Neto", Paulo Cezar Novais"', Daniela Gattas'v, Camila Albuquerque Mello de Carvalhov ${ }^{v}$, Daniela Pretti da Cunha Tirapelliv', Carlos Augusto Fernandes Molina VII, Luis Fernando TirapellivIII, Silvio Tucci Junior ${ }^{\mathrm{IX}}$

'Master, Postgraduate Program in Clinical Surgery, Department of Surgery and Anatomy, School of Medicine of Ribeirao Preto, Universidade de São Paulo (USP), Ribeirao Preto-SP, Brazil. Acquisition and interpretation of data, manuscript writing.

"Pos-doctoral Fellow student, Postgraduate Program in Clinical Surgery, Department of Surgery and Anatomy, School of Medicine of Ribeirao Preto, USP, Ribeirao Preto-SP, Brazil. Technical procedures, manuscript writing.

"'Assistant Professor, Department of Health Sciences, Universidade de Marília, Brazil. Technical procedures, manuscript writing. IVFellow Master degree, Postgraduate Program in Clinical Surgery, Department of Surgery and Anatomy, School of Medicine of Ribeirao Preto, USP, Ribeirao Preto-SP, Brazil. Manuscript writing.

${ }^{\vee}$ Assistant Professor, Institute of Biological and Health Sciences, Federal University of Alagoas, Alagoas, Brazil and PhD Student, Clinical Surgery Postgraduate Program, Department of Surgery and Anatomy, School of Medicine of Ribeirao Preto, USP, Ribeirao Preto-SP, Brazil. Manuscript writing.

V'Assistant Professor, Department of Surgery and Anatomy, Surgical Clinic Program, School of Medicine of Ribeirao Preto, USP, Ribeirao Preto-SP, Brazil, Scientific and intellectual content of the study.

VIIAssistant Professor, Division of Urology, Department of Surgery and Anatomy, School of Medicine of Ribeirao Preto, USP, Ribeirao Preto-SP, Brazil. Scientific and intellectual content of the study.

VIIIAssociate Professor, Department of Surgery and Anatomy, School of Medicine of Ribeirao Preto, USP, Ribeirao Preto-SP, Brazil. Scientific and intellectual content of the study.

${ }^{1 \times}$ Associate Professor, Division of Urology, Department of Surgery and Anatomy, School of Medicine of Ribeirao Preto, USP, Ribeirao Preto-SP, Brazil. Concept, design, intellectual and scientific content of the study; critical revision; supervised all phases of the study.
Abstract
Purpose: To evaluate the expression of endothelial and inducible NOS in addition to the miRNA- $27 \mathrm{~b}$ in the corpus cavernosum and peripheral blood of healthy rats, diabetic rats, alcoholic rats and rats with both pathologies.
Methods: Forty eight Wistar rats were divided into four groups: control (C), alcoholic (A), diabetic (D) and alcoholic-diabetic (AD). Samples of the corpus cavernosum were prepared to study protein expressions of eNOS and iNOS by immunohistochemistry and expression of miRNA-27b in the corpus cavernosum and peripheral blood.
Results: Immunohistochemistry for eNOS and iNOS showed an increase in cavernosal smooth muscle cells in the alcoholic, diabetic and alcoholic-diabetic groups when compared with the control group. Similarly, the mRNA levels for eNOS were increased in cavernosal smooth muscle (CSM) in the alcoholic, diabetic and alcoholic-diabetic groups and miRNA-27b were decreased in CSM in the alcoholic, diabetic and alcoholic-diabetic groups.
Conclusion: The major new finding of our study was an impairment of relaxation of cavernosal smooth muscle in alcoholic, diabetic, and alcoholic-diabetic rats that involved a decrease in the nitric oxide pathway by endothelium-dependent mechanisms accompanied by a change in the corpus cavernosum contractile sensitivity.
Key words: Alcoholism. Diabetes Mellitus. Erectile Dysfunction. Rats. 


\section{Introduction}

Erectile dysfunction is characterized by a persistent inability to achieve and/or maintain an erection sufficient for satisfactory sexual performance ${ }^{1}$. In the last 25 years there has been a revolution in the treatment of Erectile Dysfunction (ED) when the role of nitric oxide (NO) in the physiology of erection can be understood and phosphodiesterase 5 (PDE5) inhibitors have been used in the treatment of $E D^{2}$.

It is estimated that the overall prevalence of erectile dysfunction (ED) is approximately $20 \%$ of the male population ${ }^{3}$. In 1995 it was estimated that there were 152 million men with ED in the world and 322 million were projected with this disease by $2025^{4}$. Prevalence increases with age and comorbidities such as type II diabetes, obesity, cardiovascular diseases, hypertension, dyslipidemia, and benign prostatic hyperplasia $(\mathrm{BPH})^{5-7}$.

Nowadays it is widely accepted that the release of NO into the cavernous tissue is the most important event triggering erection; it arises as a neurotransmitter of non-adrenergic and non-cholinergic neurons (NANC) and as vasodilator derived from the endothelium, acting in order to increase intracellular levels of cGMP in the cavernous vascular smooth muscle ${ }^{8-13}$. It is a consensus that NO derived from nitricergic nerve endings (produced by neuronal nitric oxide synthase - nNOS) is responsible for rapid and initial vasodilation, whereas endothelial NO (produced by endothelial nitric oxide synthase - eNOS) contributes to the maintenance of erection ${ }^{13}$.

Diabetics have a higher incidence of ED, probably due to vascular and neurological changes as a result of the disease, however, this dysfunction can occur even with normal glycemic indexes. Pathological alterations in the cavernous arteries, ultrastructural alterations in the smooth muscle cavernosa and decrease in endothelium relaxation dependent on the smooth muscle cavernosa were observed in samples of cavernous tissue of diabetic patients ${ }^{14,15}$.

Alcoholism hasalsobeenassociated with ED; several mechanisms are described, among which neurological, endocrine, psychological and supposed vascular alterations ${ }^{16}$. However, findings suggest that a decrease in the relaxation response of the corpus cavernosum in rats with chronic alcoholism occurs due to the decrease of the endothelial response to the cholinergic stimulant ${ }^{17}$.

In search of clarifying molecular events associated with ED present studies have analyzed the role of microRNAs (miRNA). MicroRNAs have recently been recognized as a class of short, highly conserved RNA molecules (around 22 nucleotides), which are highly conserved (among distant species), whose function seems to be to regulate gene expression at the post-transcriptional level18. The present study aims at evaluating the gene and protein expressions of iNOS and eNOS isoforms, as well as microRNA-27b in the corpus cavernosum and in the peripheral blood of rats submitted to model of alcoholism and diabetes.

\section{Methods}

A total of 48 male Wistar rats (Rattus norvegicus) from the University of São Paulo Ribeirão Preto Campus, after approval by the Ethics Committee of our institution, were used. They were divided into 4 groups and followed for 4 weeks after the adaptive period: control group (C), alcoholic group (A), diabetic group (D), alcoholic-diabetic group (AD), all groups consisting of 12 animals each.

For the animals in the ethanol group $(A$, $A D)$, the model of "semi-voluntary alcoholism" was used, in which the ethanol solution at $20 \%$ 
was the only liquid available to these animals, following a model proposed by Tirapelli in 2006, where there was an adaptive phase that consisted of the supply of ethanol in increasing weekly concentrations of 5, 10 and 20\%, starting the experimental phase after the third week of treatment ${ }^{19}$.

For the immunohistochemistry, the corpus cavernosum of control $(n=6)$, alcoholic $(n=6)$, diabetic $(n=6)$ and alcoholic-diabetic rats $(n=6)$ were immediately removed and fixed for $24 \mathrm{~h}$ in ice-cold $0.1 \mathrm{~mol} / \mathrm{I} \mathrm{PBS} \mathrm{(pH} \mathrm{7.4),}$ containing $4 \%$ paraformaldehyde, followed by cryoprotection in $15 \%$ of sucrose for $4 \mathrm{~h}$ and $30 \%$ sucrose overnight at $4 \mathrm{C}$. Immunohistochemical analyses of longitudinal sections $(10 \mu \mathrm{m})$ of the corpus cavernosum were carried out via avidinbiotin-peroxidase (Novostain Super ABC Kit Universal, NCL-ABCu, Novocastra Laboratories Ltd, Newcastle upon Tyne, UK) - (universal Kit mach 4 BIOCARE). The longitudinal sections were incubated with $3 \% \mathrm{H} 2 \mathrm{O} 2$, followed by antigen retrieval with a moist heat steam cooker Optistream Plus (Krups North America, Inc., Millville, New Jersey, USA) with $10 \mathrm{mM}$ citrate buffer at $\mathrm{pH} 6.0$ for 35 minutes. Then, the sections were incubated for 24 hours in a primary antibody: ETA and ETB diluted 1/300 in PBS solution of bovine serum albumine (BSA). Subsequently, the blocking of the endogenous biotin was performed (Biotin Blocking System, Dako North America, Inc., Carpinteria, USA) and only then the sections were incubated with secondary antibody HRP kit MACH 4-Universal Polymer (M4BD534, Biocare Medical) and then with avidin-biotin-peroxidase kit same (1/200 in PBS). Color was developed through the addition of diaminobenzidine (Sigma Chemical, St. Louis, USA.

The sections were dehydrated in ethanol, cleared with xylene and mounted under the cover slip with Permount liquid (Fisher Scientific Company LLC, Fair Lawn, New Jersey, USA).
The slides for the immunohistochemical study were analyzed using the Zeiss microscope Axioskop 2 plus model in magnification of 400 times. The number of cells with positive staining for eNOS and iNOS isoforms were measured by using a camera (Axio Cam, Zeiss, Germany) and the program Axiovision 4.6 (Zeiss, Germany). Analysis of expression profile of the miRNAs-155 and 199

The expression profile of the miRNA$27 \mathrm{~b}$ was analyzed in blood and cavernous tissue samples from each animal. Total cellular RNA was extracted using Trizol Reagent (Invitrogen, Carlsbad, CA) and RNA was reverse transcribed to single-stranded cDNA, using a High Capacity Kit (Applied Biosystems, Foster City, CA) according to the manufacturer's protocol. For the quantitative analysis of the miRNA-27b, we used the commercially available system TaqMan Assay-ondemand (Applied Biosystems). Reverse transcription was performed using $5 \mathrm{ng}$ total RNA for each sample in $7,5 \mu \mathrm{L}$ of the total reaction mixture. The cDNA obtained was diluted $1: 4$ and $4.5 \mu \mathrm{L}$ was used for each $10 \mu \mathrm{L}$ of the quantitative real-time polymerase chain reaction mixture using the TaqMan Master Mix (Applied Biosystems). All reactions were carried out in duplicate and analyzed with the 7500 Sequence Detection System apparatus (Applied Biosystems). Data were analyzed using the ABI-7500 SDS software. The total RNA absorbed was normalized on the basis of the $\mathrm{Ct}$ value for U6. The variation in expression among samples was calculated by the $2-\Delta \Delta C t$ method, with the mean $\Delta \mathrm{Ct}$ value for a group of 6 samples from control rats being used as a calibrator.

\section{Statistical analysis}

For the evaluation of all studies in this research (protein expression and gene expression), statistical analysis was performed using the Kruskal-Wallis test and Dunn's multiple comparison post-test. We used the 
GraphPad Prism program 6:00 version for Windows (GraphPad Software, San Diego California USA) and considered statistically significant $p<0.05$.

\section{- Results}

\section{Imunohistochemistry}

From the global evaluation of the labeling pattern by immunohistochemistry of the expressions of eNOS and iNOS in the cavernous bodies, in all the groups studied, low tissue expression was observed in the animals in all groups, being slightly higher in the animals of the AD group (Figures 1 and 2).

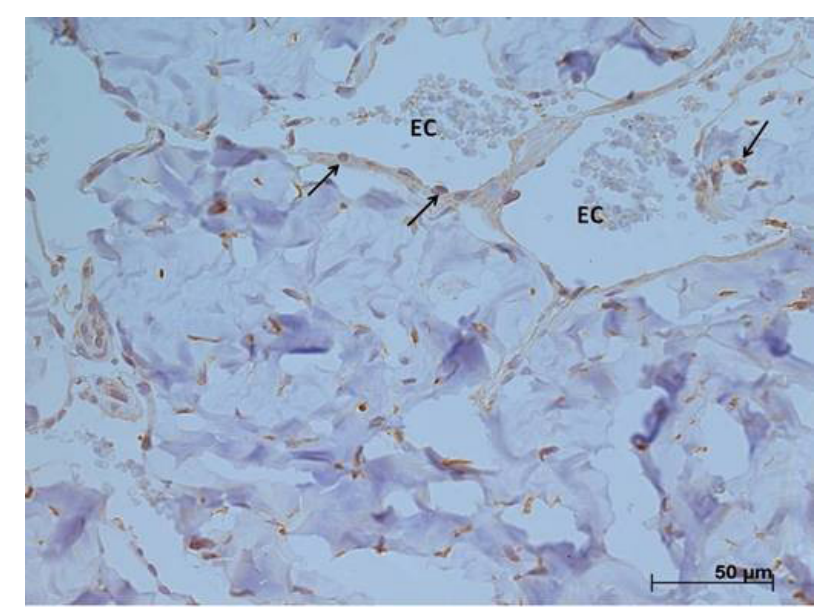

Figure 1 - Representative immunohistochemical photomicrograph of the global expression of the eNOS in rat penile tissue sections from alcoholicdiabetic rats. Observe diffuse endothelial marking in the erectile tissue. Vascular or cavernous space (CE). (x400).

\section{Expression profile of genes and miRNAs}

We found no significant difference between the groups analyzed. There was a non-significant increase in the expression profiles of the eNOS and iNOS in both D and AD groups (Figures 3 and 4).

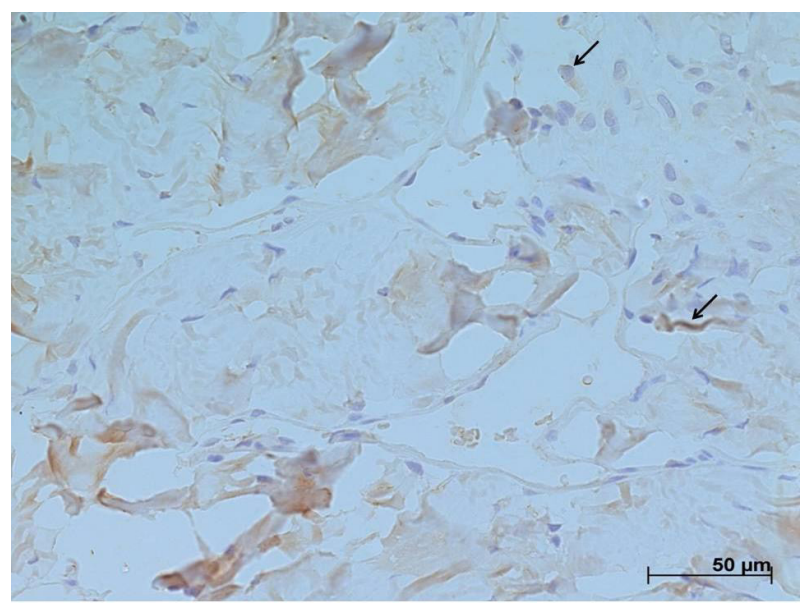

Figure 2 - Representative immunohistochemical photomicrograph of the global expression of the iNOS in rat penile tissue sections from alcoholicdiabetic rats (x400).

eNOS

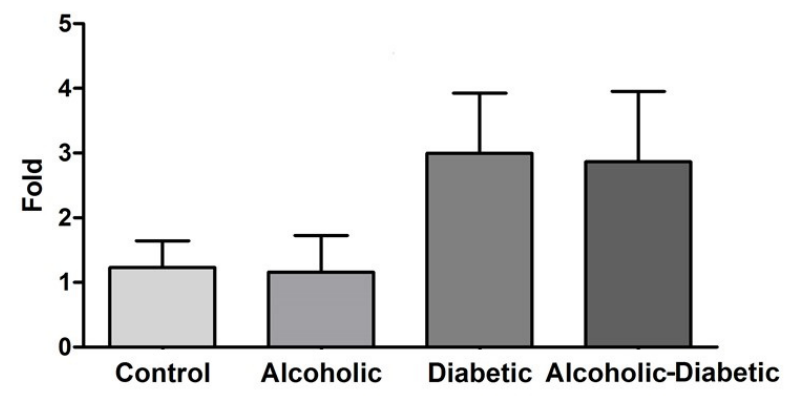

Figure 3 - Representation of mean values ( \pm standard error) of eNOS gene expression in cavernous tissue samples of the groups studied. There was no significant difference in the groups ( $p=0.0968$, Kruskall Wallis test).

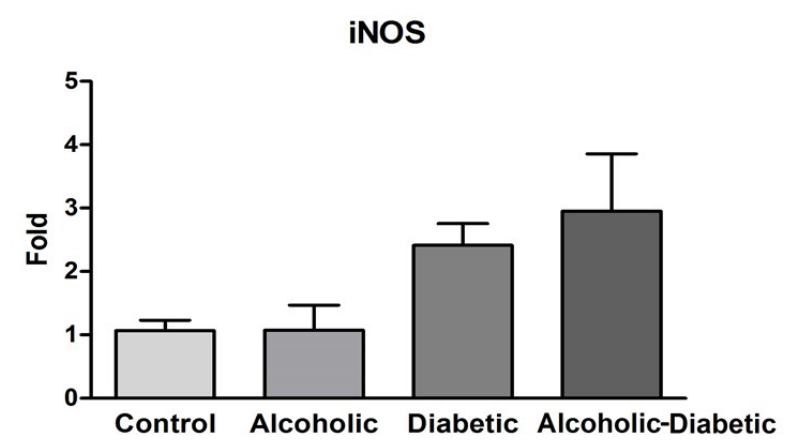

Figure 4 - Representation of mean values ( \pm standard error) of iNOS gene expression in cavernous tissue samples of the groups studied. There was no significant difference in the groups ( $p=0.0629$, Kruskall Wallis test). 
A significant decrease in the expression of miRNA-199 was observed in the tissue of the corpus cavernosum and blood of the rats in the $A D$ group when compared to the $\mathrm{C}$ group (Figure 5).
$\operatorname{miR-27b}$

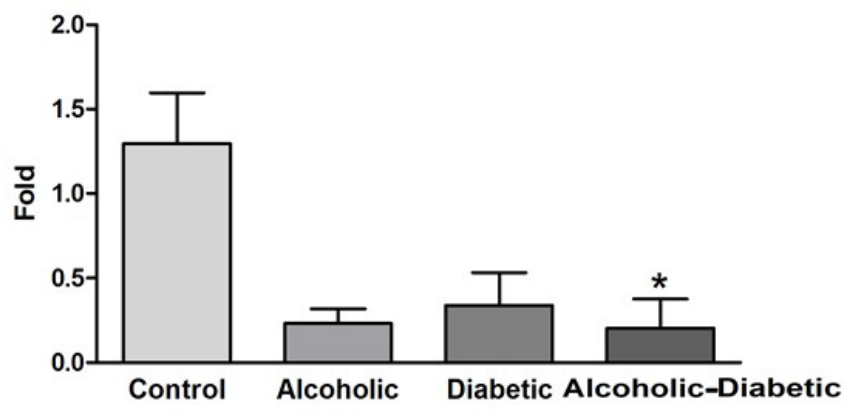

miR-27b blood

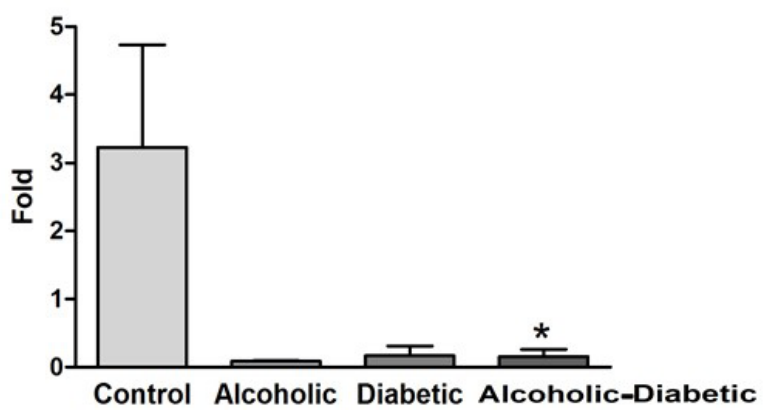

Figure 5 - Representation of mean values ( \pm standard error) of microRNA-27b expression in the blood and cavernous tissue samples of the groups studied. There was a significant difference between the control group and the alcoholic group (Kruskall Wallis test, ${ }^{*} p<0.05$, Kruskall Wallis test, Dunn's post-test).

\section{- Discussion}

Penile erection is a complex neurovascular process dependent on the relaxation of the smooth muscle of the corpora cavernosa and NO, which has been shown to be released from the nerves, is the major relaxing agent in several mammals 20,21 .

Lizarte et al. investigated the effect of diabetes mellitus and chronic ethanol consumption on the relaxation mediated by nitric oxide in the smooth muscle of the cavernous bodies of rats for four weeks ${ }^{22,23}$. When performing the analysis of immunohistochemistry and gene expression by real-time PCR, high expressions of eNOS and iNOS were observed in the smooth muscle fibers of the rats in the three groups, ethanol, diabetic and diabetic associated to the chronic consumption of ethanol, when compared to the animals in the control group. These studies demonstrated a decrease in the acetylcholineinduced relaxation capacity in the musculature of the corpora cavernosa via the endotheliumdependent mechanism suggesting, therefore, that the chronic consumption of ethanol induces endothelial dysfunction. Compared to the described findings, similar results were demonstrated in our study in the analysis of the eNOS and iNOS gene expressions of the animals in the diabetic and diabetic alcoholic groups, and also an increase in the eNOS and mainly iNOS expressions in the animals in the alcoholic diabetic group.

Our results demonstrated, through the time PCR technique, increased gene expressions of eNOS and iNOS in the group of diabetic animals and also in the group of diabetic animals associated with alcoholism. In the results of the eNOS and iNOS protein expression analysis by immunohistochemistry, diffuse expression was observed in the cavernosal tissue of both eNOS and iNOS where eNOS presented greater expression in the alcoholic-diabetic group and iNOS also presented increased expression in the alcoholic-diabetic group but a higher expression still in the group of animals submitted to alcoholism alone.

Recent studies have shown that specific classes of miRNAs affect the function of endothelial cells that are involved in many aspects of vascular biology, producing different factors that regulate smooth muscle cell proliferation and vascular tone. Among 
these, miRNA-27b has been reported to have a significant role in the angiogenesis of endothelial cells ${ }^{24}$. Our results demonstrated low gene expression of miRNA-27b in the blood and corpus cavernosum of alcoholic, diabetic and alcoholic-diabetic groups, when compared to control group. We know, however, that the suppression of miRNA-27b by ethanol may be responsible for the inhibition of angiogenesis of the endothelial cells, suggesting that the suppression of its expression inhibits the formation of endothelial cells, thus promoting an imbalance in the regulatory mechanisms of nitric oxide that are essential for the occurrence of angiogenesis. As a result, chronic alcoholism plays an important role in the pathogenesis of erectile dysfunction.

Our results demonstrated a possible regulation of the eNOS and iNOS isoforms by microRNA-27b, since they showed opposite expression levels, that is, the gene and protein expressions of eNOS and iNOS were increased in the diabetic and alcoholic-diabetic groups while the expression of microRNA-27b was low in the same groups.

\section{Conclusions}

The major new finding of our study was an impairment of relaxation of cavernosal smooth muscle in ethanol, diabetic, and ethanol-diabetic rats that involved a decrease in the nitric oxide pathway by endotheliumdependent mechanisms accompanied by a change in the corpus cavernosum contractile sensitivity. Early diagnosis and treatment of complex diseases such as erectile dysfunction, alcoholism, and diabetes may benefit from miRNAs studies designed to identify diseasespecific molecular markers that provide a fingerprint of the condition or to identify potential therapeutic targets. Rapid advances in the field of genomics offer new diagnoses and potential for screening even for diseases such as erectile dysfunction, alcoholism, and diabetes.

\section{References}

1. Cirino G, Fusco F, Imbimbo C, Mirone V. Pharmacology of erectile dysfunction in man. Pharmacol Ther. 2006 Aug;111(2):40023. PMID: 16443277.

2. Derogatis LR, Burnett AL. The epidemiology of sexual dysfunctions. J Sex Med. 2008 Feb;5(2):289-300. PMID: 18004994.

3. Burnett AL. Phosphodiesterase 5 mechanisms and therapeutic applications. Am J Cardiol. 2005 Dec;96(12B):29M-31M. PMID: 16387563.

4. Ayta IA, McKinlay JB, Krane RJ. The likely worldwide increase in erectile dysfunction between 1995 and 2025 and some possible policy consequences. BJU Int. 1999 Jul;84(1):50-6. PMID: 10444124.

5. Braun M, Sommer F, Lehmacher W, Raible A, Bondarenko B, Engelmann U. Erectile dysfunction. Are interdisciplinary diagnosis and therapy necessary?. Dtsch Med Wochenschr. 2004 Jan;129(4):131-6. PMID: 14724773.

6. Martin-Morales A, Sanchez-Cruz JJ, Saenz de Tejada I, Rodriguez-Vela L, Jimenez-Cruz JF, Burgos-Rodriguez R. Prevalence and independent risk factors for erectile dysfunction in Spain: results of the epidemiologia de la disfuncion erectil masculina study. J Urol. 2001 Aug;166(2):569-74. PMID: 11458070.

7. Selvin E, Burnett AL, Platz EA. Prevalence and risk factors for erectile dysfunction in the US. Am J Med. 2007 Feb;120(2):151-7. PMID: 17275456.

8. Holmquist F, Stief CG, Jonas $U$, Andersson KE. Effects of the nitric oxide synthase inhibitor NG-nitro-L-arginine on the erectile response to cavernous nerve stimulation in the rabbit. Acta Physiol Scand. 1991 Nov;143(3):299-304. PMID: 1722938.

9. Kim N, Azadzoi KM, Goldstein I, Saenz de Tejada I. A nitric oxide-like factor mediates nonadrenergic-noncholinergic neurogenic relaxation of penile corpus cavernosum smooth muscle. J Clin Invest. 1991 Jul;88(1):112-8. PMID: 1647413.

10. Burnett AL, Lowenstein CJ, Bredt DS, Chang 
TS, Snyder SH. Nitric oxide: a physiologic mediator of penile erection. Science. 1992 Jul;257(5068):401-3. PMID: 1378650.

11.Burnett AL, Nelson RJ, Calvin DC, Liu JX, Demas GE, Klein SL, et al. Nitric oxidedependent penile erection in mice lacking neuronal nitric oxide synthase. Mol Med. 1996 May;2(3):288-96. PubMed PMID: 8784782. PMCID: PMC2230154. eng.

12.Burnett AL, Tillman SL, Chang TS, Epstein JI, Lowenstein CJ, Bredt DS, Snyder SH, Walsh PC. Immunohistochemical localization of nitric oxide synthase in the autonomic innervation of the human penis. J Urol. 1993 Jul;150(1):73-6. PMID: 7685426.

13.Trigo-Rocha F, Aronson WJ, Hohenfellner M, Ignarro LJ, Rajfer J, Lue TF. Nitric oxide and CGMP: mediators of pelvic nerve-stimulated erection in dogs. Am J Physiol. 1993 Feb;264(2 Pt 2):H419-22. PMID: 8383456.

14.Michal V, Kramár R, Pospíchal J, Ruzbarský V, Simána J, Blazková J, et al. Vascular surgery in the treatment of impotence; its present possibilities and prospects. Czech Med. 1980;3(3):213-7. PMID: 7438942.

15. Mersdorf A, Goldsmith PC, Diederichs W, Padula CA, Lue TF, Fishman IJ, Tanagho EA. Ultrastructural changes in impotent penile tissue: a comparison of 65 patients. J Urol. 1991 Apr;145(4):749-58. PMID: 2005694.

16. Troncale JA. Endocrine effects of alcoholism. J Fam Pract. 1984 Jul;19(1):17, 21-2, 25 passim. PMID: 6736879.

17.Saito M, Broderick GA, Wein AJ, Levin RM. Effect of chronic ethanol consumption on the pharmacological response of the rabbit corpus cavernosum. Pharmacology. 1994 Dec;49(6):386-91. PMID: 7878076.

18. Urbich C, Kuehbacher A, Dimmeler S. Role of microRNAs in vascular diseases, inflammation, and angiogenesis. Cardiovasc Res. 2008Sep;79(4):581-8. PMID: 18550634. 19.Tirapelli CR, Casolari DA, Montezano AC, Yogi $A$, Tostes RC, Legros $E, D^{\prime}$ Orléans-Juste P, Lanchote VL, Uyemura SA, de Oliveira AM. Ethanol consumption enhances endothelin1 -induced contraction in the isolated rat carotid. J Pharmacol Exp Ther. 2006 Aug;318(2):819-27. PMID: 16651399.

20.Andersson KE, Wagner G. Physiology of penile erection. Physiol Rev. 1995 Jan;75(1):191-236. PMID: 7831397.

21.Sáenz de Tejada I, Angulo J, Cellek S, González-Cadavid N, Heaton J, Pickard R, Simonsen U. Pathophysiology of erectile dysfunction. J Sex Med. 2005 Jan;2(1):2639. PMID: 16422902.

22.Lizarte FS, Claudino MA, Tirapelli CR, Morgueti $M$, Tirapelli DP, Batalhão $M E$, Carnio EC, Queiroz RH, Evora PR, Tucci S Jr, Cologna A, Antunes E, Martins AC, Tirapelli LF. Chronic ethanol consumption induces cavernosal smooth muscle dysfunction in rats. Urology. 2009 Dec;74(6):1250-6. PMID: 19615717.

23.Lizarte FS, Morgueti M, Tirapelli CR, Claudino MA, Evora PR, Novais PC, Tirapelli DP, Celotto AC, Capellini VK, Celini FP, Tucci S Jr, Cologna AJ, Antunes E, Martins AC, Tirapelli LF. Chronic alcoholism associated with diabetes impairs erectile function in rats. BJU Int. 2010 Jun;105(11):1592-7. PMID: 20132198.

24.Staszel T, Zapała B, Polus A, SadakierskaChudy A, Kieć-Wilk B, Stępień E, Wybrańska I, Chojnacka M, Dembińska-Kieć A. Role of microRNAs in endothelial cell pathophysiology. Pol Arch Med Wewn. 2011 Oct;121(10):361-6. PMID: 21946298. 


\section{Correspondence:}

Joao Paulo da Cunha

Faculdade de Medicina de Ribeirão Preto, USP

Avenida Bandeirantes, 3900

14049-900 Ribeirão Preto - SP Brasil

Tel.: (55 16)3315-3305

lab.biomol.cirurgia@fmrp.usp.br

Conflict of interest: none

Financial sources: none
Received: Sep 15, 2016

Review: Nov 17, 2016

Accepted: Dez 18, 2016

${ }^{1}$ Research performed at Molecular Biology Laboratory, Department of Surgery and Anatomy, Medical School of Ribeirao Preto, Universidade de São Paulo (USP), Brazil. 